\title{
Pengaruh Iklim Organisasi, Kepemimpinan dan Kepuasan Kerja Terhadap Kinerja Pegawai SAMSAT Provinsi Sumatera Utara
}

\section{The Effect Of Organizational Climate, Leadership and Job Satisfaction On The Performance Of SAMSAT Emloyees North Sumatra Province}

\author{
Dedy Irvan Caniago* \\ Universitas Terbuka, Indonesia
}

Disubmit: 18 September 2021; Diproses: 18 September 2021; Diaccept: 09 Oktober 2021; Dipublish: 02 Desember 2021

*Corresponding author: E-mail: dedichaniagout@gmail.com

\begin{abstract}
Abstrak
Penelitian ini bermaksud untuk menganalisis, mengevaluasi pengaruh iklim organisasi, kepemimpinan, dan kepuasan kerja terhadap kinerja pegawai pada kantor Samsat Provinsi Sumatera Utara. Populasi penelitian yang digunakan sebanyak 755 karyawan. Penentuan sampel menggunakan rumus Slovin. Jumlah sampel yang diperoleh sebanyak 90 orang dan dialokasikan secara proporsional. Pengumpulan data menggunakan kuesioner dan skala likert. Untuk menganalisis data dilakukan penelitian dengan bantuan software SPSS versi 26. Berdasarkan hasil analisis diketahui bahwa variabel iklim organisasi berpengaruh positif terhadap kinerja pegawai Samsat Provinsi Sumatera Utara, variabel kepemimpinan berpengaruh positif terhadap kinerja pegawai, dan variabel kepuasan kerja berpengaruh positif terhadap kinerja pegawai. . Selanjutnya secara bersama-sama iklim organisasi, kepemimpinan, dan kepuasan juga berpengaruh positif terhadap kinerja pegawai Samsat Provinsi Sumatera Utara. Kata Kunci: Iklim Organisasi; Kepemimpinan Kerja; Kinerja Pegawai
\end{abstract}

\begin{abstract}
This study intends to analyze, evaluate the influence of organizational climate, leadership, and job satisfaction on the performance of employees at the Samsat office of North Sumatra Province. The research population used consisted of 755 employees. The determination of the sample using the Slovin formula. The number of samples obtained as many as 90 people and allocated proportionally. Data were collected using a questionnaire and Likert scale. To analyze the data, the research was carried out with the help of SPSS version 26 software. Based on the analysis, it is known that organizational climate variables have a positive influence on the performance of Samsat employees in North Sumatra Province, leadership variables have a positive influence on employee performance, and job satisfaction variables have a positive influence on employee performance. . Furthermore, together the organizational climate, leadership, and satisfaction also have a positive influence on the performance of the Samsat employees of North Sumatra Province. Keywords: Organizational Climate; Job Satisfaction; Employee Performance
\end{abstract}

DOI: https://doi.org/10.51849/j-p3k.v2i3.116

Rekomendasi mensitasi :

Caniago, D,I., (2021), Pengaruh Iklim Organisasi, Kepemimpinan dan Kepuasan Kerja Terhadap Kinerja Pegawai SAMSAT Di Provinsi Sumatera Utara. Jurnal Penelitian Pendidikan, Psikologi dan Kesehatan (J-P3K), 2 (3): 233-238. 


\section{PENDAHULUAN}

Beberapa penelitian yang pernah dilakukan kinerja pegawai meningkat disebabkan adanya pengaruh dar iklim organisasi. Dimana iklim organisasi berakibat pada terciptanya lingkungan yang senantiasa memberikan motivasi, persepsi karyawan yang pada akhirnya pada meningkatnya kinerja karyawan. Iklim organisasi menyebabkan munculnya motivasi yang berpusat pada persepsi masuk akal dan langsung berpengaruh pada kinerja anggota sebuah organisasi, Stinger dalam. Sebagai akibatnya memiliki efek eksklusif terhadap kinerja anggota organisasi yang mampu menciptakan harapan pegawai tentang konsekuensi hadir dari tindakan. Karyawan berharap menerima imbalan, rasa puas yang mendasari persepsi mereka terhadap iklim organisasi(Robert Kreitner, 2014)

Kepemimpinan menjadi sebuah sikap, kebiasaan, serta karakter pribadi. Pemimpin seyogyanya selalu berintrospeksi ketika memimpin orang lain serta terus belajar memimpin diri sendiri, dikarenakan kepemimpinan akan tumbuh dari dalam diri dan juga memiliki relevansi dengan iklim organisasi. Iklim organisasi dilihat atas lima dimensi antara lain responsibility atau tanggung jawab, Identity atau identitas, Warmth atau kehangatan, Support atau dukungan, dan Conflict atau konflik. Kepemimpinan serta iklim organisasi yang baik diperlukan untuk menghasilkan kinerja yang tinggi dan memberi keuntungan pada organisasi Kepemimpinan menunjukkan adanya kemampuan pemimpin atau juga disebut leader yang mempengaruhi orang yang dipimpin (Tubagus, 2015)
SAMSAT merupakan akronim dari Sistem Administrasi Manunggal Satu Atap (SAMSAT). Dimana Pemerintah Daerah Provinsi Sumatera Utara menaungi SAMSAT yang berperan pada bidang layanan publik secara eksklusif pada masyarakat misalnya menerbitkan STNK, TNKB, PKB, BBNKB, Surat Tanda Coba Kendaraan Bermotor, serta Sumbangan Wajib Dana Kecelakaan Lalu Lintas Jalan (SWDKLJJ). Selain menerbitkan dan mencetak buku surat-surat kendaraan bermotor, Kantor SAMSAT juga memiliki target penerimaan pajak dan asuransi yang perlu dicapai. Berikut capaian target penerimaan pajak dan asuransi tahun 2019 (PERPRES NO.5 TAHUN 2015, 2015)

Berdasarkan hasil pengamatan di kantor Samsat, masih ditemukan adanya pegawai yang bermain handphone disaat jam kerja, masih adanya pegawai yang menggunakan fasilitas internet untuk membuka sosial media dijam kerja, izin keluar pada saat jam kerja, datang tidak tepat waktu, dan pulang lebih awal. Hal ini dapat disebabkan oleh kurang tegasnya pimpinan dalam melakukan pengawasan, teguran bahkan sanksi yang tegas. Berdasarkan informasi dari Kasub Tata Usaha Samsat terkait daftar hadir kantor, bahwa selama kurun waktu tahun 2019 jumlah terbanyak adalah izin saat jam kerja dengan total 74. Hal ini mengindikasikan bahwa terdapat pegawai yang mengabaikan kedisplinan selama jam kerja. Demikian pula dengan keadaan pegawai yang pulang lebih awal sebanyak 46 izin pulang dengan berbagai alasan. Data di atas seharusnya menjadi perhatian dari pimpinan untuk dievaluasi 
Masalah-masalah yang diuraikan di atas tidak menutup kemungkinan terjadi karena dipengaruhi oleh beberapa faktor seperti iklim organisasi, kepemimpinan, dan kepuasan kerja yang dialami oleh pegawainya. Akibatnya, kinerja pegawai pada kantorpun masih sangat sulit untuk diperbandingkan dari waktu ke waktu dikarenakan, masih ada pegawai yang kinerjanya masih sama dari hari ke hari dan belum mengalami peningkatan maksimal. Akibatnya, tidak sedikit pula ditemukan adanya keluhan dari masyarakat tentang lamanya pengurusan surat-surat kendaraan, hal ini tentunya berkaitan erat dengan kinerja pegawai Samsat itu sendiri

\section{METODE PENELITIAN}

Studi yang dilakukan oleh peneliti ini merupakan penelitian kuantitatif yang memanfaatkan pendekatan deskriptifverifikatif. Dalam penelitian yang penulis lakukan, objek penelitian yang diteliti yaitu Iklim Organisasi, Kepemimpinan, Kepuasan Kerja, serta Kinerja pegawai di lingkungan Samsat provinsi Sumatera Utara. Sedangkan yang dijadikan sebagai subjek dalam penelitian ini Seluruh pegawai di bawah naungan Samsat provinsi Sumatera Utara.

Populasi yang digunakan sebagai subjek yang akan diteliti sebanyak 755 orang pegawai. Dengan menggunakan teknik penentuan sampel pertimbangan tertentu, maka jumlah sampel sebanyak 90 responden. Adapun pengumpulan data penelitian ini melalui teknik survey langsung, dimana lembar kuesioner dengan skala likert disebarkan kepada responden. Peneliti terjun langsung untuk mendapatkan data dari sejumlah responden melalui kuesioner yang difokuskan kepada seluruh pegawai yang bertugas di kantor Samsat yang ada di bawah naungan provinsi daerah Sumatera Utara.

Pada penelitian ini, teknik analisis data yang digunakan diantaranya analisis regresi ganda, pengujian hipotesis menggunakan uji parsial, uji anova, dan analisis koefisien determinasi dengan terlebihi dahulu melakukan uji asumi klasik dari seluruh data variabel penelitian yang telah diperoleh.

\section{HASIL DAN PEMBAHASAN}

1. Hasil Uji Validitas Instrumen

Hasil uji validitas pada variabel iklim organisasi, kepemimpinan, kepuasan kerja, dan kinerja menggunakan korelasi Product Moment diperoleh bahwa dari seluruh indikator yang diujikan menunjukkan nilai nilai thitung $>$ tabel, nilai sig. $<0,05$ yang berarti bahwa seluruh instrumen penelitian valid.

2. Hasil Uji Asumsi Klasik

Hasil uji normalitas One-Sample Kolmogorov-Smirnov Test diperoleh Sig. (2-tailed) sebesar 0,200 lebih besar dari 0,05 (data berdistribusi normal), sehingga asumsi atau persyaratan normalitas dalam model regresi terpenuhi. Selanjutnya untuk mengetahui bahwa antara variabel independen tidak saling berkorelasi signifikan, maka dilakukan uji multikolinearitas dimana nilai VIF kurang dari 10,00 dan nilai Tolerance lebih dari 0,10 . Kesimpulannya tidak ditemukan tanda-tanda multikolinearitas dalam model regresi.

Untuk menguji heteroskedastisitas agar diperoleh metode regresi yang baik, dipilih uji Glejser sebagai acuan. Adapun 
hasil pengujian nilai signifikansi iklim organisasi $\left(X_{1}\right)=0,209$, kepemimpinan $\left(\mathrm{X}_{2}\right)=0,129$, dan Kepuasan Kerja $\left(\mathrm{X}_{3}\right)=$ 0,168 . Oleh karena nilai signifikansi semua variabel tersebut berada di atas 0,05 maka disimpulkan tidak terjadi tanda-tamda heterosdastisitas pada contoh regresi.

3. Hasil Analisis Regresi Linier Ganda dan Uji Hipotesis

Persamaan regresi didapat dari analisis regresi ganda dari variabel Kinerja Pegawai atas faktor-faktor yang berpengaruh yaitu iklim organisasi, kepemimpinan dan kinerja pegawai. Hasil hitung dapat dicermati dalam tabel 3 berikut:

Tabel 1. Regresi Linear Ganda

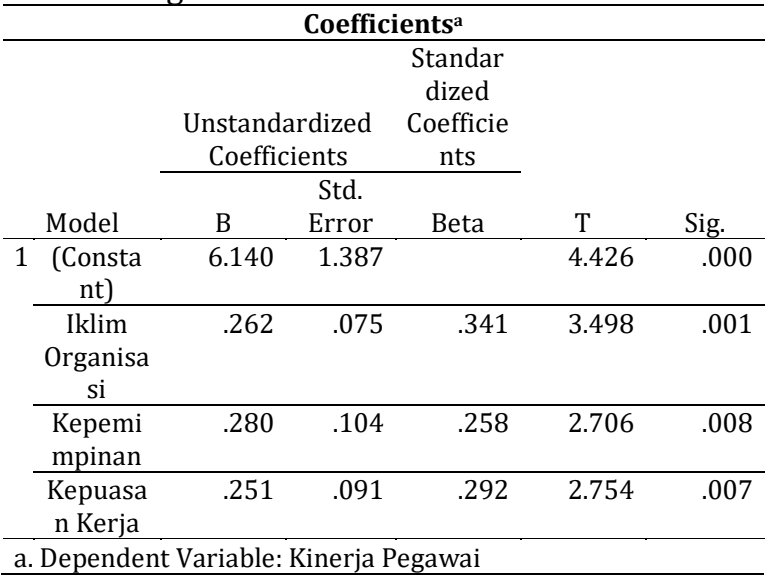

Hubungan antara variabel dependen dengan independen ditunjukkan dengan persamaan $\mathrm{Y}=6,140+0,262 \mathrm{X}_{1}+0,280 \mathrm{X}_{2}$ $+0,251 X_{3}$. Koefisien regresi variabel iklim organisasi, kepemimpinan, dan kepuasan kerja seluruhnya bernilai positif, artinya seluruh variabel bebas memberikan pengaruh positif terhadap kinerja pegawai.

Begitu pentingnya iklim organisasi dalam sebuah organisasi menjadi salah satu fokus yang menarik perhatian peneliti di bidang perilaku keorganisasian. Iklim organisasi merupakan salah satu aspek kajian dari fungsi MSDM yakni fungsi pemeliharaan karyawan agar tujuan organisasi dapat tercapai.

Suasana lingkungan kerja yang dirasakan oleh masing-masing individu dalam sebuah organisasi sering disebut sebagai iklim organisasi. Kurang diperhatikannya iklim organisasi akan membawa dampak buruk bagi organisasi, hal ini dikarenakan para pegawai akan mengalami gangguan dalam melaksanakan pekerjaannya sehingga kurang bersemangat dalam menyelesaikan pekerjaannya.

Penelitian terdahulu yang dilakukan oleh (Murniaty \& Absah, 2012)mengenai Pengaruh Iklim Organisasi Terhadap Kinerja Karyawan Bagian Pemasaran Pada PT Telkom Divisi Telkom Flexi Medan. Hasil yang diperoleh dalam penelitian tersebut menunjukkan bahwa thitung yang diperoleh sebesar sebesar 3,955 > nilai ttabel 1,671 dengan sig $0,000<0,05$ sehingga dapat disimpulkan bahwa iklim organisasi berpengaruh secara signifikan terhadap kinerja karyawan bagian pemasaran PT Telkom Divisi telkom Flexi Medan.

Penelitian yang dilakukan oleh (Karundeng, 2013), Juga menunjukkan bahwa iklim organisasi memiliki kontribusi pengaruh sebesar 82,05 \% terhadap kinerja karyawan pada PT Taspen Cabang Manado.Iklim organisasi merupakan suatu kondisi atau cerminan dari budaya yang terbentuk. Iklim organisasi yang baik dalam bekerja menimbulkan kenyamanan, saling menghormati dan kebersamaan dalam bekerja. (SAHRENI, 2016)

Iklim organisasi yang baik menjadi modal awal suatu organisasi untuk dapat mempengaruhi perilaku para anggota 
organisasi dan dapat membentuk nilai karakteristik dari organisasi tersebut. (sugus, 2018)Iklim organisasi merupakan sebuah konsep yang menggambarkan suasana internal lingkungan organisasi yang dirasakan anggotanya selama mereka beraktivitas dalam rangka tercapainya tujuan organisasi. Iklim dapat bersifat menekan, netral atau dapat pula bersifat mendukung. Iklim organisasi (atau disebut juga suasana organisasi) adalah serangkaian lingkungan kerja di sekitar tempat kerja yang berpengaruh terhadap perilaku seseorang dalam melaksanakan pekerjaan. (Satria \& Kuswara, 2013)

\section{SIMPULAN}

Kesimpulan dalam penelitian ini diantaranya, kinerja pegawai dalam Kantor SAMSAT Pemprovsu ditentukan faktorfaktor diantaranya iklim organisasi, kepemimpinan dan kepuasan kerja. Nilai R-Square $(61,1 \%)$ menaruh makna bahwa iklim organisasi, kepemimpinan dan kepuasan kerja mempengaruhi kinerja pegawai sebesar $61,1 \%$, sedangkan sisanya $(39,9 \%)$ merupakan efek faktor-faktor tidak ikut diteliti dalam penelitian ini. Iklim organisasi, kepemimpinan dan kepuasan kerja bersama-sama memberikan efek positif dan signifikan terhadap kinerja pegawai. Dan secara terpisah (parsial) iklim organisasi memberi efek positif dan signifikan pada kinerja pegawai, kepemimpinan menaruh efek positif dan signifikan pada kinerja pegawai, serta kepuasan kerja menaruh efek positif dan signifikan pada kinerja pegawai pada Kantor Samsat Pemprovsu.

Hasil penelitian ini diinginkan dapat dimanfaatkan sebagai acuan pada penelitian-penelitian selanjutnya yang berkaitan dengan variabel-variabel yang telah diteliti serta saran penelitian diantaranya dapat menaikkan kinerja pegawai dalam Kantor Samsat Pemrovsu, dengan terus berupaya memperhatikan setiap anggota baik itu para pegawai maupun pimpinan di jajaran Kantor SAMSAT Pemprovsu terutama dalam hal menjabarkan visi, misi, dan strategi. Terus melakukan aktivitas membentuk hubungan baik, komunikasi, memupuk rasa tanggungjawab, evaluasi dan membangun rasa cinta antara pimpinan dengan jajaran di bawahnya

\section{DAFTAR PUSTAKA}

Karundeng, C. C. (2013). Pengaruh Iklim Organisasi terhadap Karyawan pada PT. TASPEN (Persero) Cabang Manado. Jurnal Acta Diurna, 2(3), 1-15. https://ejournal.unsrat.ac.id/index.php/act adiurnakomunikasi/article/view/2433/1968

Murniaty, D., \& Absah, Y. (2012). PENGARUH IKLIM ORGANISASI TERHADAP KINERJA KARYAWAN BAGIAN PEMASARAN PADA PT TELKOM DIVISI TELKOM FLEXI MEDAN. 3(September), 119-122. https://docplayer.info/48656789-Pengaruhiklim-organisasi-terhadap-kinerjakaryawan-bagian-pemasaran-pada-pttelkom-divisi-telkom-flexi-medan.html PERPRES NO. 5 TAHUN 2015, (2015).

Robert Kreitner, A. K. (2014). Perilaku Organisasi. Salemba Empat. https://openlibrary.telkomuniversity.ac.id/

SAHRENI, I. (2016). HUBUNGAN GAYA KEPEMIMPINAN MANAJER KEPERAWATAN. August.

Satria, R. O., \& Kuswara, A. (2013). Pengaruh Motivasi Dan Pelatihan Terhadap Kompetensi Kerja Serta Implikasinya Pada Produktivitas Pegawai Dinas Perhubungan Kota Bandung. Jurnal Ekonomi, Bisnis \& Entrepreneurship, $\quad 7(2), \quad 74-83$. http://jurnal.stiepas.ac.id/index.php/jebe/a rticle/view/31

sugus, permen. (2018). Teori kepemimpinan. https://doi.org/10.31219/osf.io/bzvqu 
Tubagus, A. D. (2015). Konsep-Konsep Dasar Manajemen Personalia Masa Kini. PT. Refika Aditama. https://perpustakaan.kpu.go.id/article

Karundeng, C. C. (2013). Pengaruh Iklim Organisasi terhadap Karyawan pada PT. TASPEN (Persero) Cabang Manado. Jurnal Acta Diurna, 2(3), 1-15. https://ejournal.unsrat.ac.id/index.php/act adiurnakomunikasi/article/view/2433/1968

Murniaty, D., \& Absah, Y. (2012). PENGARUH IKLIM ORGANISASI TERHADAP KINERJA KARYAWAN BAGIAN PEMASARAN PADA PT TELKOM DIVISI TELKOM FLEXI MEDAN. 3(September), 119-122. https://docplayer.info/48656789-Pengaruhiklim-organisasi-terhadap-kinerjakaryawan-bagian-pemasaran-pada-pttelkom-divisi-telkom-flexi-medan.html PERPRES NO.5 TAHUN 2015, (2015).

Robert Kreitner, A. K. (2014). Perilaku Organisasi. Salemba Empat. https://openlibrary.telkomuniversity.ac.id/

SAHRENI, I. (2016). HUBUNGAN GAYA KEPEMIMPINAN MANAJER KEPERAWATAN. August.

Satria, R. O., \& Kuswara, A. (2013). Pengaruh Motivasi Dan Pelatihan Terhadap Kompetensi Kerja Serta Implikasinya Pada Produktivitas Pegawai Dinas Perhubungan Kota Bandung. Jurnal Ekonomi, Bisnis \& Entrepreneurship, $\quad 7(2), \quad 74-83$. http://jurnal.stiepas.ac.id/index.php/jebe/a rticle/view/31

sugus, permen. (2018). Teori kepemimpinan. https://doi.org/10.31219/osf.io/bzvqu

Tubagus, A. D. (2015). Konsep-Konsep Dasar Manajemen Personalia Masa Kini. PT. Refika Aditama. https://perpustakaan.kpu.go.id/article 